\title{
Judgement of political statements are influenced by speaker identity
}

\author{
Brian Bi (brianbi@berkeley.edu) \\ Department of Psychology, 2121 Berkeley Way \\ Berkeley, CA 94704 USA \\ Louis Martí (I_Am_A_Robot@berkeley.edu) \\ Department of Psychology, 2121 Berkeley Way \\ Berkeley, CA 94704 USA \\ David O'Shaughnessy (oshd@ berkeley.edu) \\ Department of Psychology, 2121 Berkeley Way \\ Berkeley, CA 94704 USA \\ Celeste Kidd (celestekidd@berkeley.edu) \\ Department of Psychology, 2121 Berkeley Way \\ Berkeley, CA 94704 USA
}

\begin{abstract}
Analyses of political discourse typically focus on the semantic content of politicians' statements. The approach treats the meaning of a speaker's words as independent from the speaker's identity itself; however, there are reasons to believe that one might influence the other. Features of a speaker's identity influence others' judgements of their character (e.g., Kinzler \& DeJesus, 2013), and thus speaker identity could influence listeners' assessment of the semantics and validity of the statements themselves. Here, we collect U.S. participants' judgements of the political orientation of different statements, from liberal to conservative, heard with one of three accents, a generic U.S. accent, a Southern U.S. accent or an Australian accent. In comparison to identical statements conveyed in the generic U.S. accent, participants tended to perceive the U.S. Southern accented statements as more conservative and the Australian accented statements as more liberal.
\end{abstract}

Keywords: Language; sociolinguistics; social cognition.

\section{Introduction}

Dictionaries definitions map words onto meanings and concepts, irrespective of the person who is speaking them. However, we know from several decades of work in contemporary linguistics that language is ambiguous, and that listeners consider the context when interpreting the meaning of statements they make (e.g., Tanenhaus et al., 1995; Spivey et al., 2002; Chomsky, 2006; Piantadosi et al., 2012). For example, the homonyms "genes" and "jeans" sound the same, but refer to entirely different referents in the world. Despite the potential for confusion that this could create, listeners in the real world have no problem employing context to understand the speaker's intended meaning. The context includes the words and discussion topic around the homonym (e.g., "I got a kit from 23 andMe to learn more about my genes" vs "I went to the store to buy a pair of jeans"), but also the context of the speaker themselves. A biologist in a scientific talk just saying the word "genes" in isolation would be more likely to conjure up the biological definition in the mind of the listener, while someone standing on a catwalk at a fashion show producing the same sound would more likely be interpreted as referring to the clothing item (Clark, 1988).

\section{Accent encodes features of speaker identity}

Speech accents are one way in which people communicate and gain access to one another's backgrounds. They reveal information about a person's geographic origins, cultural background, age, ethnicity, socioeconomic class, education values, and more (Labov, 1963). In a study of young adults at Martha's Vineyard, Labov found that the degree to which a youth used local-dialect features predicted whether or not they intended to leave the area to attend college: young adults who planned to stay had more features of the regional dialect than those who intended to leave.

It would thus make sense that listeners employed the information encoded in these cues when interpreting people's utterances. Previous work has shown that, in fact, listeners use features of speakers' accents to form beliefs about their character, sometimes revealing hidden biases and racism (Kinzler et al., 2009). People with Southern accents, for example, are deemed to be less educated and less trustworthy than those without accents (Amira et al., 2018; Ash et al., 2020). 


\section{Southern U.S. accents are associated with negative} personal attributes

Ash and colleagues hired actors to deliver speeches on partisan issues in different U.S. accents as fake candidates, and then asked participants about their expectations and preferences for the candidates they heard. Participants evaluated candidates with Southern U.S. accents more harshly, regardless of the political position espoused in the speech, consistent with other work suggesting Southern accents are associated with negative personal attributes (e.g., Amira et al., 2018; Ash et al., 2020; Kinzler \& DeJesus, 2013). Further, they found that U.S. voters expected Southern U.S. accents to be associated with typical Republican issue positions than Democratic ones (Ash et al., 2020).

Remarkably, even children used speech accents to form beliefs about the character of other people (Kinzler \& DeJesus, 2013). Kinzler and DeJesus evaluated the developmental trajectory of U.S. children's use of accent in evaluating speakers and found differences in preference as early as 5 years, with children preferring to befriend Northern-accented speakers than Southern-accented ones. By 10 years old, children evaluated Northern U.S. accents as indicating greater competence (associated with adjectives like "smarter" and "in charge"), and Southern U.S. accents as indicating friendliness (associated with "nicer"). These effects were robust to whether the child themselves came from a region with a Southern or Northern U.S. accent, and are consistent with accent biases observed in adults.

\section{Beyond speaker identity}

Here, we test whether accented speech not only colors the listener's perceptions of the speaker, but also their assessment of the statement itself. This issue is particularly important given the regional variation in accents even within the U.S. as well as the largely regional variation in political views. Specifically, we evaluate whether participants' judgements of the political orientation of a statement is impacted by the speaker's accent. We test three accent conditions with U.S. participants: a generic U.S. accent ${ }^{1}$, a Southern U.S. accent, and an Australian accent.

We find that participants' characterization of the political statements is significantly impacted by the accent of the speaker, with statements spoken in Southern U.S. accents characterized as more conservative and those spoken in Australian accents characterized as more liberal. This demonstration illustrates that people's interpretation of the underlying meaning of a statement is influenced by contextual information - in this case, the identity of the speaker as revealed by the speech accent

\section{Methods}

\section{Experiment}

Stimuli We recorded 52 different statements spoken by three different speakers, ranging from more liberal (e.g., "Because corporations cannot be trusted to voluntarily protect the environment, they require regulation"), to more conservative (e.g., "Our civil liberties are being excessively curbed in the name of counter-terrorism."), as determined by judgements of the participants. Each of the speakers possessed either a generic U.S., Southern U.S., or Australian accent. The Australian accent served as a control to allow us to test whether any differences that might be observed between the generic U.S. and Southern U.S. accents could be due to decreased familiarity or perceived "otherness" of the Southern accented speech.

The speakers who recorded these statements were closely matched for speech rate, vocal pitch, and prosody to prevent potential differences in these features from acting as experimental confounds. Participants in this study were randomly assigned to one of three conditions so that they only heard one accent in order to mask what the study was about. Thus, this is an across-subject design.

Statements heard by participants were 1 sentence long and were read off to the participant as soon as they began the study and completed a preliminary audio check. Participants were given the option to replay the stimuli if needed and were required to rate each statement before hearing the next statement. (See Appendix for 52 statements.)

Participants heard all 52 statements, and 5 statements were repeated and randomly selected and placed throughout the survey for all of the participants. In total, the participants listened to 57 statements (including the 5 repeated reliability trials).

Task We tested 109 participants on Amazon Mechanical Turk on August 12th, 2020. Participants listened to at least one of two audio checks prior to the start of the experiment to test for audio issues. The participants were asked to type the spoken word that was said at the beginning of the survey. The spoken word was either "banana" or "zebra". Participants were compensated at a rate of $\$ 10.00$ per hour.

The instructions told participants that they would hear 52 different political statements. The participants were then

\footnotetext{
${ }^{1}$ We refer to "generic U.S." to mean that our reference condition is an American English accent widely perceived as free of any specific local, ethnic, or cultural dialect features, of the kind that is popularly used in U.S. media broadcasts. This kind of speech is sometimes referred to as "General English" or "Standard American English". We disprefer these latter terms because they suggest widespread consensus on a single standard dialect when this is not the case.
} 
randomly assigned to listen to one of the three accents. For each statement, we asked participants to rate how conservative or liberal each specific statement was. All participants listened to the 52 political statements in a randomized order. Participants in our study used a 7-point Likert scale to rate each of the 52 statements, 1 being most conservative and 7 being most liberal or in other words, the response measured the liberalness of the specific statements that the participants heard.

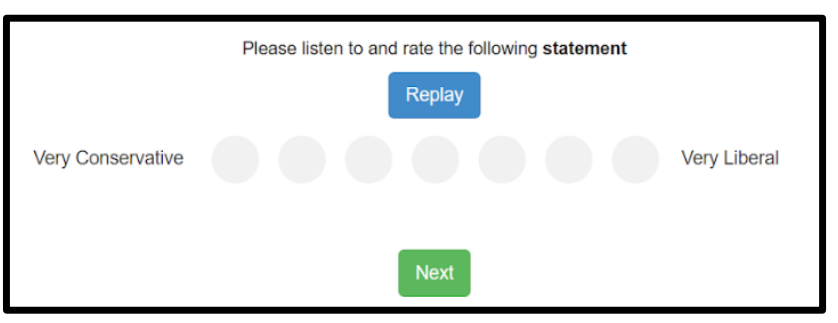

Figure 1: Participants heard 52 randomized statements and rated each of the statements they heard on a 7-point scale as shown above.

\section{Results}

Figure 2 shows the scaled mean liberalness rating for statements in each accent condition, with generic U.S. as the reference. In line with previous work on accent, the U.S. participants here rated the Southern U.S. accent as being least liberal, and the Australian accent as being most liberal.

Table 1 shows the results of our regression analysis, which show that the mean differences we observed in liberalness ratings of the Australian and Southern U.S. accent conditions differ significantly different from the generic U.S. accent, and in opposite directions.

\section{Analysis}

In quantifying how accented speech color the listeners' perception of the speaker along with their assessment of the statement itself, we can compare the average liberalness ratings of each statement heard by each of the accent conditions. By doing so, we can better understand how accented speech affect the meaning of statements and concept formation. We standardized each of our liberalness statement ratings by subtracting the mean of the total liberalness rating and divided it by the standard deviation of the liberalness rating. From here we ran a regression analysis between the scaled standardized liberalness rating and accent conditions.

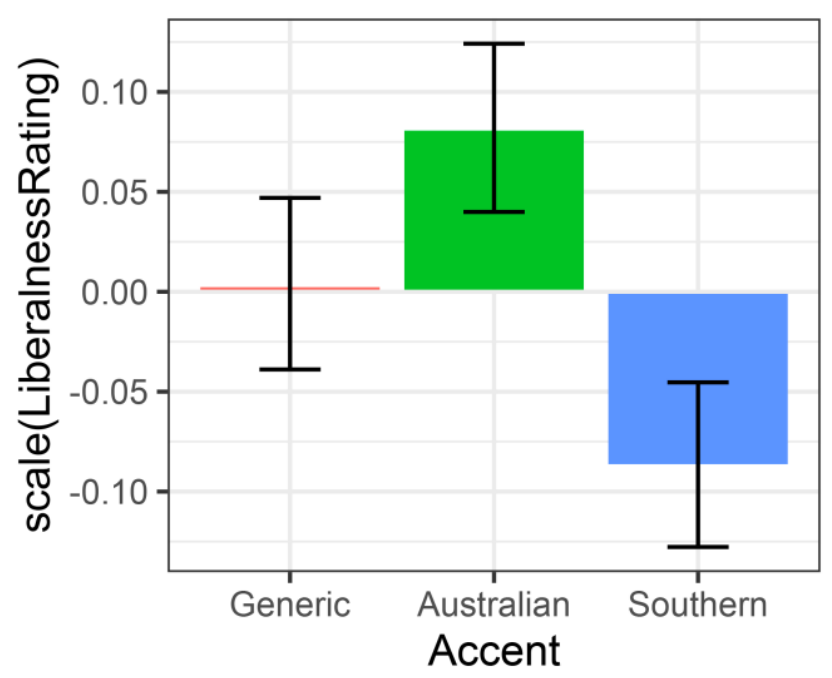

Figure 2: Scaled mean liberalness ratings across the three different accent conditions. Error bars show $95 \%$ confidence intervals.

Table 1: Regression coefficients for stimuli accent response

\begin{tabular}{lcccc} 
Term & Coef. & SE & $t$ & $p$ \\
\hline Generic U.S. & 0.00336 & 0.02 & 0.153 & 0.87868 \\
Australian & 0.0783 & 0.03 & 2.532 & $0.01136 *$ \\
Southern U.S. & -0.0901 & 0.03 & -2.912 & $0.00361 * *$ \\
\hline
\end{tabular}

Figure 3 shows the scaled liberalness rating for each accent condition by item, with the items ordered from most liberal on average to most conservative from left to right. As you can see in this plot, the trends observed in the means generally hold across most items, with some variation. Across items, items conveyed in a Southern U.S. accent are judged as relatively more conservative, regardless of where the items fall on the overall political spectrum.

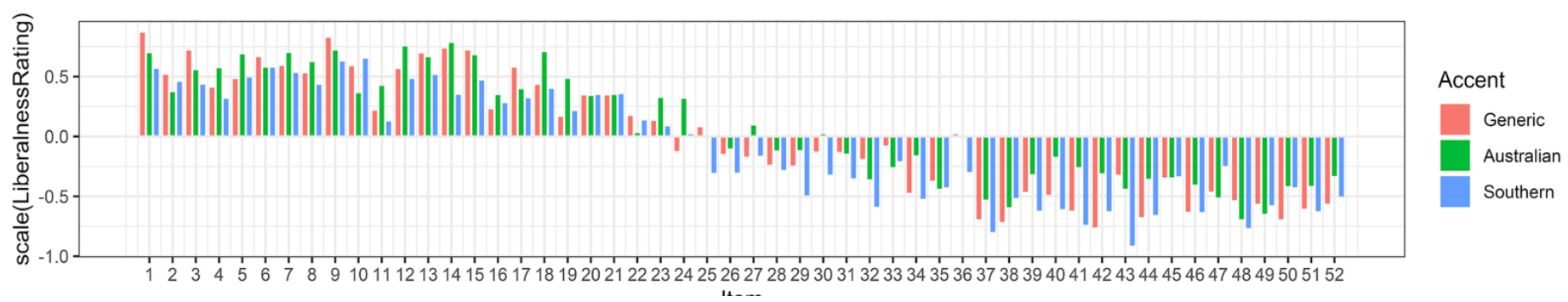

Figure 3: Scaled liberalness ratings by item. Even within most items, Southern U.S.-accented statements are judged to be less liberal than generic U.S.- or Australian-accented ones. 


\section{Summary}

The results suggest that participants judge statements conveyed in Southern-accented speech as themselves being more conservative, despite the fact that these statements were, word for word, identical to those conveyed in the generic U.S. accent. In contrast, participants judged the statements read by the Australian English speaker to be more liberal than the generic U.S. accent condition, thus ruling out the possibility the observed differences between liberalness judgements of generic and Southern U.S. speech are due to lack of familiarity or "otherness". These results suggest that the identity of the speaker impacts not only listeners' assessments of the speaker (e.g., Kinzler \& DeJesus, 2013), but also their interpretation of the meaning of the statements.

\section{Discussion \& Conclusion}

Our results demonstrate people use social contextual cues when interpreting the meaning of utterances. This is beyond what has been demonstrated previously, which focused on how accented speech impacted listeners' expectations about personal attributes of the speaker themselves.

These results have important implications for understanding political discourse and ideological disagreements, which overwhelmingly focus on the semantics of the statements. Our results suggest that meaning and presentation cannot be easily separated by listeners, and indeed listeners are subject to implicit biases about the content of statements. In one sense, this might be a sensible adaptation to a speech environment in which conservative views do tend to come from those speaking southernaccented speech, but equally one would hope that in issues as important as politics, it would be possible for people to separate out form and content. These results may have implications for understanding the relationship between speech and the political climate, and indicate that speech community identity may play an important role in people's political decisions.

\section{Further developments and future work}

Further work with this data will evaluate interactions between the listeners own identity and accented speech and their liberalness ratings of each candidate using demographic information we collected from each participant. We expect that, most likely, that a speakers' own identity will not impact their tendency to interpret Southern U.S. statements as more conservative, in light of the previous work showing that the personal attributes and stereotypes associated with Southern U.S. accents are consistent across U.S. speakers generally, including those with Southern U.S. accents.

Our next set of work will examine whether speaker accent has an impact on listeners' likelihood of adopting the espoused belief themselves, which could be expected given existing associations between Southern U.S. accents and a lack of trustworthiness.

\section{References}

Achen, C. H. (1975). Mass political attitudes and the survey response. American Political Science Review, 69(4), 1218-1231.

Ash, K., Johnson, W., Lagadinos, G., Simon, S., Thomas, J., Wright, E., \& Gainous, J. (2020). Southern Accents and Partisan Stereotypes: Evaluating Political Candidates. Social Science Quarterly, 101(5), 1951-1968.

Amira, K., Cooper, C. A., Knotts, H. G., \& Wofford, C. (2018). The southern accent as a heuristic in American campaigns and elections. American Politics Research, 46(6), 1065-1093.

Chomsky, N. (2006). Language and mind. Cambridge University Press.

Clark, H. H. (1998). Communal lexicons. Context in language learning and language understanding, 6387.

Coppock, A., \& McClellan, O. A. (2019). Validating the demographic, political, psychological, and experimental results obtained from a new source of online survey respondents. Research \& Politics, 6(1), 2053168018822174.

Eysenck, H.J. (1953). "Primary social attitudes: A comparison of attitude patterns in England, Germany, and Sweden". Journal of Abnormal and Social Psychology. 48(4), 563-8.

Eysenck, H.J. (1956). Sense and nonsense in psychology. London: Penguin Books.

Heaton, H., \& Nygaard, L. C. (2011). Charm or harm: Effect of passage content on listener attitudes toward American English accents. Journal of Language and Social Psychology, 30(2), 202-211.

Kinzler, K. D., \& DeJesus, J. M. (2013). Northern= smart and Southern= nice: The development of accent attitudes in the United States. Quarterly Journal of Experimental Psychology, 66(6), 1146-1158.

Kinzler, K. D., Shutts, K., DeJesus, J., \& Spelke, E. S. (2009). Accent trumps race in guiding children's social preferences. Social Cognition, 27(4), 623-634.

Labov, W. (1963). The social motivation of a sound change. Word, 19(3), 273-309.

Piantadosi, S. T., Tily, H., \& Gibson, E. (2012). The communicative function of ambiguity in language. Cognition, 122(3), 280-291.

Spivey, M. J., Tanenhaus, M. K., Eberhard, K. M., \& Sedivy, J. C. (2002). Eye movements and spoken language comprehension: Effects of visual context on syntactic ambiguity resolution. Cognitive Psychology, 45(4), 447-481.

Sumner, M., Kim, K. S., King, E., McGowan, B. K. (2014). The socially weighed encoding of spoken words: a dualroute approach to speech perception.

Tanenhaus, M. K., Spivey-Knowlton, M. J., Eberhard, K. M., \& Sedivy, J. C. (1995). Integration of visual and linguistic information in spoken language comprehension. Science, 268(5217), 1632-1634. 


\section{Appendix: Statements and Raw Ratings by Accent Condition}

\begin{tabular}{|c|c|c|c|c|}
\hline Item & Statement & Generic U.S. & Southern U.S. & Australian \\
\hline 1 & $\begin{array}{l}\text { A same sex couple in a stable, loving relationship should not be excluded } \\
\text { from the possibility of child adoption. }\end{array}$ & 5.79 & 5.15 & 5.43 \\
\hline 2 & There are no savage and civilized peoples; there are only different cultures. & 5.05 & 4.92 & 4.74 \\
\hline 3 & $\begin{array}{l}\text { Multinational companies are unethically exploiting the plant genetic } \\
\text { resources of developing countries. }\end{array}$ & 5.48 & 4.88 & 5.13 \\
\hline 4 & Governments should penalize businesses that mislead the public. & 4.82 & 4.63 & 5.17 \\
\hline 5 & $\begin{array}{l}\text { Because corporations cannot be trusted to voluntarily protect the } \\
\text { environment, they require regulation. }\end{array}$ & 4.97 & 5.00 & 5.41 \\
\hline 6 & No one chooses his or her country of birth, so it's foolish to be proud of it. & 5.36 & 5.18 & 5.18 \\
\hline 7 & All authority should be questioned. & 5.21 & 5.08 & 5.44 \\
\hline 8 & Astrology accurately explains many things. & 5.08 & 4.87 & 5.27 \\
\hline 9 & Possessing marijuana for personal use should not be a criminal offence. & 5.70 & 5.28 & 5.48 \\
\hline 10 & $\begin{array}{l}\text { It is regrettable that many personal fortunes are made by people who simply } \\
\text { manipulate money and contribute nothing to their society. }\end{array}$ & 5.20 & 5.33 & 4.73 \\
\hline 11 & $\begin{array}{l}\text { "from each according to his ability, to each according to his need" is a } \\
\text { fundamentally good idea. }\end{array}$ & 4.42 & 4.23 & 4.85 \\
\hline 12 & $\begin{array}{l}\text { What goes on in a private bedroom between consenting adults is no } \\
\text { business of the state. }\end{array}$ & 5.15 & 4.97 & 5.55 \\
\hline 13 & Land shouldn't be a commodity to be bought and sold. & 5.43 & 5.05 & 5.36 \\
\hline 14 & $\begin{array}{l}\text { If economic globalization is inevitable, it should primarily serve humanity } \\
\text { rather than the interests of trans-national corporations. }\end{array}$ & 5.51 & 4.69 & 5.61 \\
\hline 15 & $\begin{array}{l}\text { Pornography, depicting consenting adults, should be legal for the adult } \\
\text { population. }\end{array}$ & 5.48 & 4.95 & 5.39 \\
\hline 16 & $\begin{array}{l}\text { Our civil liberties are being excessively curbed in the name of counter- } \\
\text { terrorism. }\end{array}$ & 4.44 & 4.55 & 4.69 \\
\hline 17 & Schools should not make classroom attendance compulsory. & 5.18 & 4.63 & 4.79 \\
\hline 18 & $\begin{array}{l}\text { It's a sad reflection on our society that something as basic as drinking water } \\
\text { is now a bottled, branded consumer product. }\end{array}$ & 4.87 & 4.80 & 5.45 \\
\hline 19 & $\begin{array}{l}\text { A genuine free market requires restrictions on the ability of predator } \\
\text { multinationals to create monopolies. }\end{array}$ & 4.31 & 4.41 & 4.98 \\
\hline 20 & It's natural for children to keep some secrets from their parents. & 4.68 & 4.69 & 4.68 \\
\hline 21 & People are ultimately divided more by class than by nationality. & 4.68 & 4.71 & 4.69 \\
\hline 22 & Some people are naturally unlucky. & 4.32 & 4.24 & 4.02 \\
\hline 23 & $\begin{array}{l}\text { When you are troubled, it's better not to think about it, but to keep busy } \\
\text { with more cheerful things. }\end{array}$ & 4.24 & 4.14 & 4.64 \\
\hline 24 & There is now a worrying fusion of information and entertainment. & 3.67 & 4.00 & 4.63 \\
\hline 25 & $\begin{array}{l}\text { A significant advantage of a one-party state is that it avoids all the } \\
\text { arguments that delav progress in a democratic political system. }\end{array}$ & 4.13 & 3.28 & 3.93 \\
\hline
\end{tabular}


26 Charity is better than social security as a means of helping the genuinely

27 The enemy of my enemy is my friend.

28 The death penalty should be an option for the most serious crimes.

29 The prime function of schooling should be to equip the future generation to

30 The freer the market, the freer the people.

31 Although the electronic age makes official surveillance easier, only reproduce.

33 Protectionism is sometimes necessary in trade.

34 Those with the ability to pay should have access to higher standards of

36 Making peace with the establishment is an important aspect of maturity.

37 Those who are able to work, and refuse the opportunity, should not expect society's support.

38 These days openness about sex has gone too far.

39 Military action that defies international law is sometimes justified.

40 Abstract art that doesn't represent anything shouldn't be considered art at

41 The most important thing for children to learn is to accept discipline.

42 Abortion, when the woman's life is not threatened, should always be illegal.

44 It is important that my child's school instills religious values.

45 In a civilized society, one must always have people above to be obeyed and

46 No one can feel naturally homosexual.

47 Taxpayers should not be expected to prop up any theatres or museums that

49 Sex outside marriage is usually immoral.

50 The businessperson and the manufacturer are more important than the writer and the artist. its shareholders.

52 It is a waste of time to try to rehabilitate some criminals. 